\title{
Microsporum ferrugineum
}

National Cancer Institute

\section{Source}

National Cancer Institute. Microsporum ferrugineum. NCI Thesaurus. Code C127735.

A species of anthropophilic fungi in the phylum Ascomycota characterized by "bamboo hyphae". This species is a causative agent of juvenile tinea capitis in humans. 